\title{
Preparation of Nano-TiO 2 Thin Film Using Spin Coating Method
}

\author{
Ayodele Abeeb Daniyan ${ }^{1,2 *}$, Lasisi Ejibunu Umoru ${ }^{1}$, Bankole Olunlade ${ }^{2}$ \\ ${ }^{1}$ Department of Materials Science and Engineering, Obafemi Awolowo University, Ile Ife, Nigeria \\ ${ }^{2}$ Engineering Materials Development Institute, Akure, Nigeria \\ Email: *daniyanayodele@yahoo.com
}

Received April 3, 2013; revised May 5, 2013; accepted May 15, 2013

Copyright (C 2013 Ayodele Abeeb Daniyan et al. This is an open access article distributed under the Creative Commons Attribution License, which permits unrestricted use, distribution, and reproduction in any medium, provided the original work is properly cited.

\begin{abstract}
This paper presented the preparation of $\mathrm{TiO}_{2}$ thin film on empty glass and Indium Tin Oxide (ITO) glass by spin coating method. Highly transparent titanium oxide thin films were obtained. The Optical absorption and transmission of the film prepared from both the synthesized and the commercially available $\mathrm{TiO}_{2}$ were measured by the UV-Visible Spectrophotometer. A sharp absorption edge of the $\mathrm{TiO}_{2}$ film was observed. The estimated energy band gap for the film of the commercially available sample was larger than that of the synthesized one.
\end{abstract}

Keywords: Titanium Dioxide; ITO; Spin Coating; Absorption; Band Gap

\section{Introduction}

Nanotechnology is a part of science and technology that is about the control of matter on the atomic and molecular scale-this means things that are about 100 nanometres or smaller. Nanotechnology includes making products that use these small parts such as electronic devices, catalysts, sensors, etc. Some of the most current research and development activities are in the area of functional nanotechnology. This term also describes applications in which material nanostructures are used to produce optical electronics or magnetic properties [1].

Titanium dioxide (also known as titanium (IV) oxide or Titania) is the naturally occurring oxide of titanium with chemical formula $\mathrm{TiO}_{2}$. It has a wide range of applications, from paint to sunscreen to food colouring. Titanium dioxide $\left(\mathrm{TiO}_{2}\right)$ has attracted significant attention from researchers because of the many interesting physical and chemical properties that make it suitable for a variety of applications. For instance, $\mathrm{TiO}_{2}$ has high corrosion resistance and chemical stability, excellent optical transparency in the visible and near infrared regions as well as high refractive index that makes it useful for antireflection coatings in optical devices [2]. It has been used mostly as a pigment in paints, sunscreens, ointments toothpaste etc. Therefore, this work seeks to investigate the structural and the optical properties of synthesized

${ }^{*}$ Corresponding author. nano- $\mathrm{TiO}_{2}$ for opto-electronics applications.

Recently, titanium oxide $\left(\mathrm{TiO}_{2}\right)$ thin films have been emerged as one of the most promising oxide materials owing to their optical, electrical and photo electrochemical properties.

Many studies on synthesis of $\mathrm{TiO}_{2}$ and its thin films formed by conventional and advanced sol-gel processes have been reported. Previous studies indicate that the properties of $\mathrm{TiO}_{2}$ films appear to strongly depend on the process conditions and starting materials used in the processes. Therefore, many researchers have used sol-gel method to synthesize $\mathrm{TiO}_{2}$. For instance, synthesis of nano rutile $\mathrm{TiO}_{2}$ powder at low temperature by sol-gel method using $\mathrm{Ti}\left(\mathrm{OC}_{4} \mathrm{H}_{9}\right)_{4}$ and $\mathrm{HNO}_{3}$ with mean particle size of about $50 \mathrm{~nm}$ after calcination at $600^{\circ} \mathrm{C}$ in rutile phase has been reported by [3]. Similarly, the photocatalytic activity of nano-sized $\mathrm{TiO}_{2}$ powders by sol-gel method, using $\mathrm{Ti}\left(\mathrm{OC}_{3} \mathrm{H}_{7}\right)_{4}$ (titanium isopropoxide ) and EtOH/ $\mathrm{H}_{2} \mathrm{O}$ solution has been shown by [4] and the particle size obtained were $7.9 \mathrm{~nm}$ and $7.4 \mathrm{~nm}$ respectively. Likewise, [5] also studied the preparation and characterization of nano- $\mathrm{TiO}_{2}$ powder by sol-gel method whose result yielded a mean size of about $10 \mathrm{~nm}$ after calcination. By similar method, the microstructure control of thermally stable $\mathrm{TiO}_{2}$ obtained by hydrothermal process has been investigated by [6]. They reported 13 and $34 \mathrm{~nm}$ in average diameter after calcinations at $600^{\circ} \mathrm{C}$ and $800^{\circ} \mathrm{C}$ respectively. Furthermore, by sol gel route, the 
synthesis, processing and characterization of nano- $\mathrm{TiO}_{2}$ was studied by [7]. The results obtained were $5-10 \mathrm{~nm}$ in diameter after calcination at $400^{\circ} \mathrm{C}, 22.6-29.3 \mathrm{~nm}$ after $600^{\circ} \mathrm{C}$ and the average particle size of $46.2 \mathrm{~nm}$ was obtained after calcinations at $800^{\circ} \mathrm{C}$ in pure rutile phase.

\section{Experimental Procedure}

1) Synthesis of $\mathrm{TiO}_{2}$ (rutile)

5 grams of chitosan powder was poured into a vessel containing $100 \mathrm{ml}$ of deionized water and $5 \mathrm{ml}$ of acetic acid. The mixture was stirred for $6 \mathrm{~h}$ at $90^{\circ} \mathrm{C}$, and finally cooled naturally to room temperature. 10 grams of this as-synthesized chitosan solution was added dropwise into a vessel containing $40 \mathrm{ml}$ of acetone and $4 \mathrm{ml}$ of $\mathrm{TiCl}_{3}$ solution (the precursor). Thereafter, the vessel was covered with parafilm and left at room temperature for 2 weeks. The resulting white deposit was immersed in water to dissolve the chitosan, and then the suspension was centrifuged and washed several times with deionized water and ethanol. Finally, the powder was dried at $60^{\circ} \mathrm{C}$ [8].

2) Preparation of $\mathrm{TiO}_{2}$ thin film

A commercially available $\mathrm{TiO}_{2}$ powder was gotten to comparatively study the synthesized $\mathrm{TiO}_{2}$ powder sample.

The commercially available $\mathrm{TiO}_{2}$ powder and the synthesized $\mathrm{TiO}_{2}$ were used to prepare $\mathrm{TiO}_{2}$ thin film on both empty glass substrate and Indium Tin Oxide (ITO) coated glass substrate using Spin coater. Prior to the preparation of $\mathrm{TiO}_{2}$ thin film, the glass substrate and the Indium Tin Oxide (ITO) coated glass substrate used were cut and ultrasonically cleaned by degreasing with acetone, methanol, rinsed in iso-propanol, kept in staining jar and allow to dry in vacuum oven.

$5 \mathrm{mg}$ of commercially available powder of $\mathrm{TiO}_{2}$ and synthesized sample were thoroughly mixed with $5 \mathrm{ml}$ of Polyethylene oxide (PEO) solution. The resulting colloidal solution was spin coated on glass substrate and ITO at $1500 \mathrm{srpm}$. The thickness of the film were measured using the weight differential method [9].

\section{Results and Discussion}

The results are shown in Figures 1-11 and Table 1.

X-ray diffraction (XRD) pattern (radiation used: $\mathrm{CuK} \alpha$ ) of both the synthesized and commercially available powder samples are shown in Figures $\mathbf{1}$ and $\mathbf{2}$ (from the diffraction patterns). There are appreciable similarities in their structures, which showed that the two samples are of similar material. The d-values of the synthesized sample obtained in this work are in agreement with the standard d-values of rutile structure with error of about \pm 1 . The average particle sizes of Figures $\mathbf{1}$ and $\mathbf{2}$ were calculated using Sherrer's equation. Sherrer's equation is as follows:

$$
\mathrm{D}=0.9 \lambda / \beta \cos \theta
$$

where $\lambda$ is the wavelength of $\mathrm{X}$-ray $(0.1540 \mathrm{~nm}), \beta$ is the full-width at half-maximum of the peak (in radian), and the $\theta$ is the Bragg's angle of the X-ray diffraction peaks.

The sharp diffraction peaks indicated the polycrystallinity of the $\mathrm{TiO}_{2}$ powder. The broadening of some peaks observed on the synthesized sample, according to [10], the broadening could be as a result of smaller crystals. Other causes of broadening are instruments used and synthesis temperature of the powder [11]. The broadening could be improved by calcination [12]. The little shift observed in the diffraction peaks that correspond to the main peaks of the synthesized samples could be caused by particle size variation [13]. Also, the correlation between the values of diffraction angles of the synthesized sample with the commercially available one with respect to the standard value of diffraction angles of rutile structure obtained by the XRD machine (Table 1) shows that the two powder samples are of the same material. According to [13], this variation in the particle size and the type of instrument (X-ray diffractometer) used could be responsible for the differences observed in the angle between the synthesized $\mathrm{TiO}_{2}$ powder and the commercially available one, compared with the standard $\mathrm{TiO}_{2}$ powder in Table 1. Hence, the structure further confirmed the sample synthesized to be rutile.

The particle size, $15.9 \mathrm{~nm}$ obtained from the synthesized sample was smaller than the commercially available one (26.7 nm) and much more smaller than $50 \mathrm{~nm}$, the result obtained by [3] who used sol gel method from $\mathrm{Ti}\left(\mathrm{OC}_{4} \mathrm{H}_{9}\right)_{4}$ precursor. The smaller particle size of the synthesized $\mathrm{TiO}_{2}$ makes its XRD pattern looks rougher than the XRD Pattern of the commercially available $\mathrm{TiO}_{2}$ powder. Reducing the particle size further to about 10 nm will cause the $\mathrm{TiO}_{2}$ to show amorphous pattern [1214].

Table 1. Diffraction angles of the synthesized (S $\left.2 \theta^{\circ}\right)$ commercially available $\mathrm{TiO}_{2}$ powder $\left(\mathrm{R} 2 \theta^{\circ}\right)$ and the standard $\left(\mathrm{STD} 2 \theta^{\circ}\right)$ with the lattice planes.

\begin{tabular}{cccc}
\hline $\mathrm{S} 2 \theta^{\circ}$ & $\mathrm{R} 2 \theta^{\circ}$ & $\mathrm{STD} 2 \theta^{\circ}$ & $\mathrm{h} \mathrm{k} 1$ \\
\hline 22.99 & 23.39 & 27.45 & 110 \\
38.47 & 35.53 & 39.19 & 200 \\
52.63 & 42.50 & 54.32 & 211 \\
63.75 & 64.17 & 64.04 & 310 \\
82.45 & 82.60 & 82.34 & 321 \\
\hline
\end{tabular}


MD-10. 11/14/11

Exposure Time: 1200/1200sec. Radiation: CuKa, avg Sample: PS

Operator: TAYO

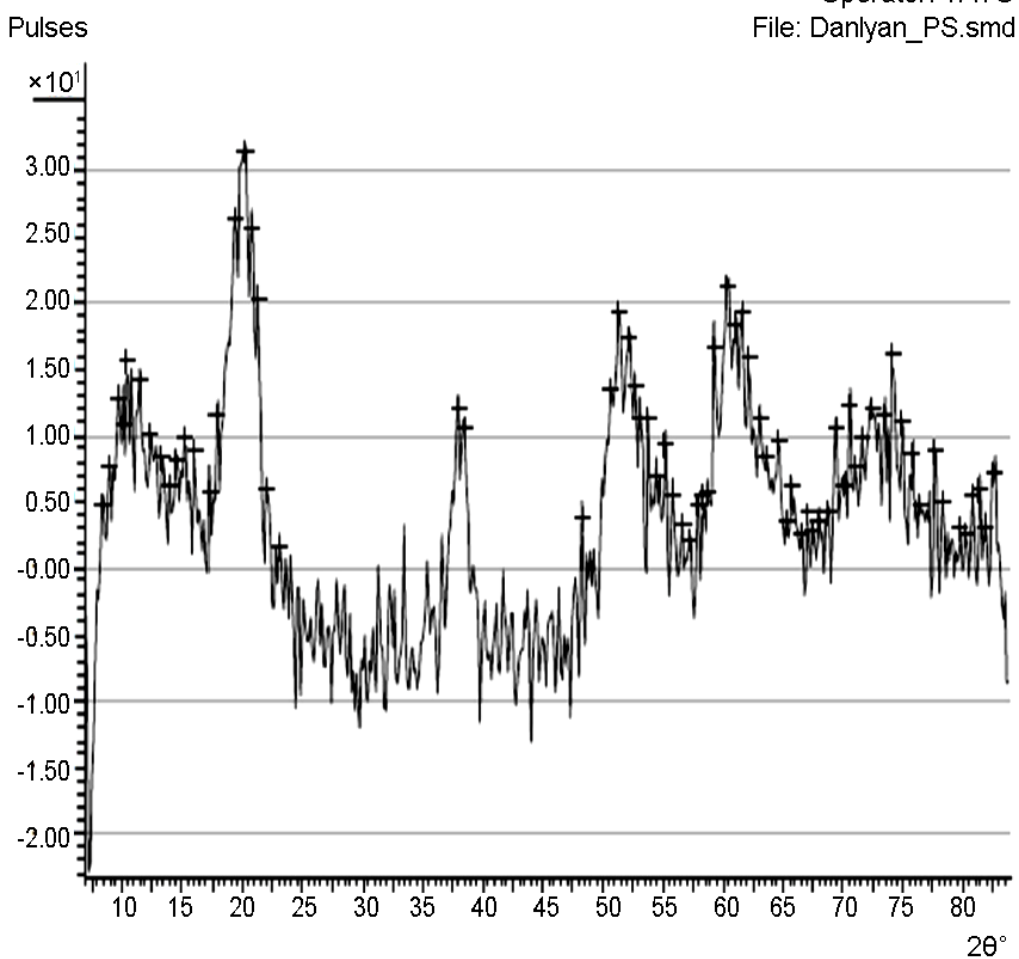

Figure 1. XRD pattern of the synthesized $\mathrm{TiO}_{2}$ powder.

MD-10. 11/14/11

Exposure Time: $1200 / 1200$ sec. Radiation: CuKa, avg Sample: PR Operator: TAYO

Pulses File: Danlyan_PR.smd

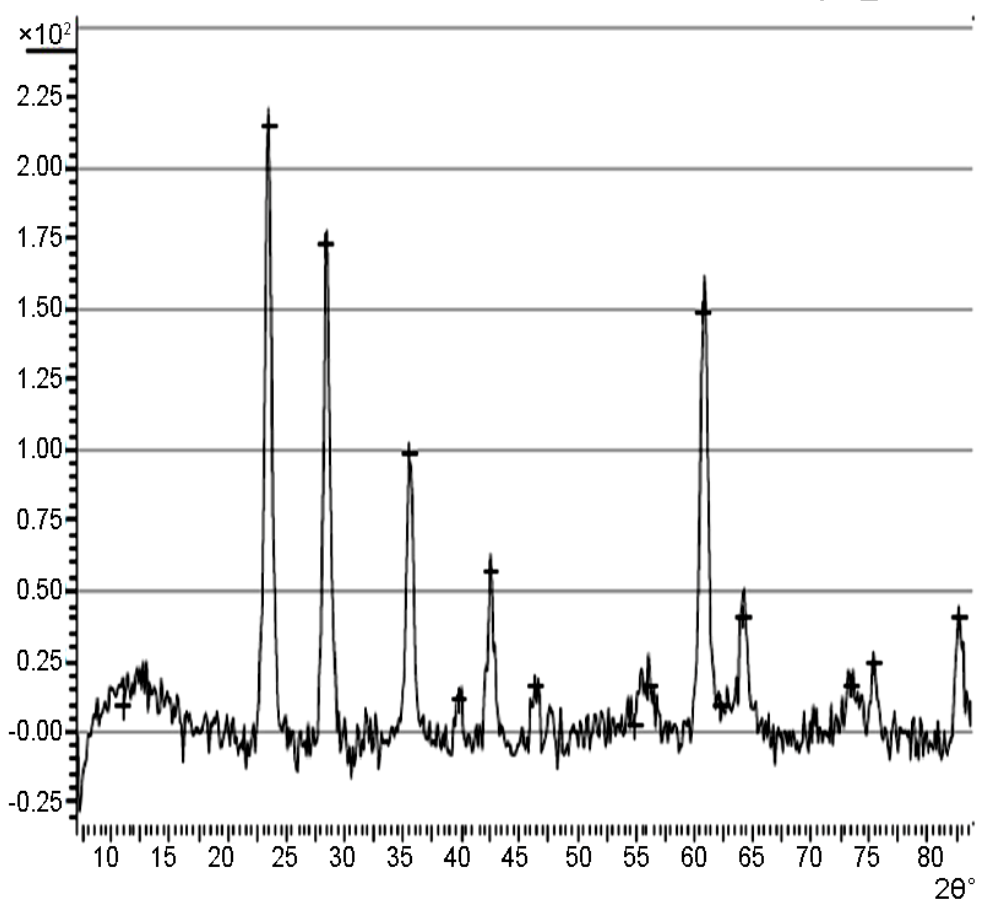

Figure 2. XRD pattern of the commercially available $\mathrm{TiO}_{2}$ powder. 
Exposure Time: 1200/1200sec. Radiation: CuKa, avg Sample: CX Operator: TAYO

Pulses

File: Danlyan_CX.smd

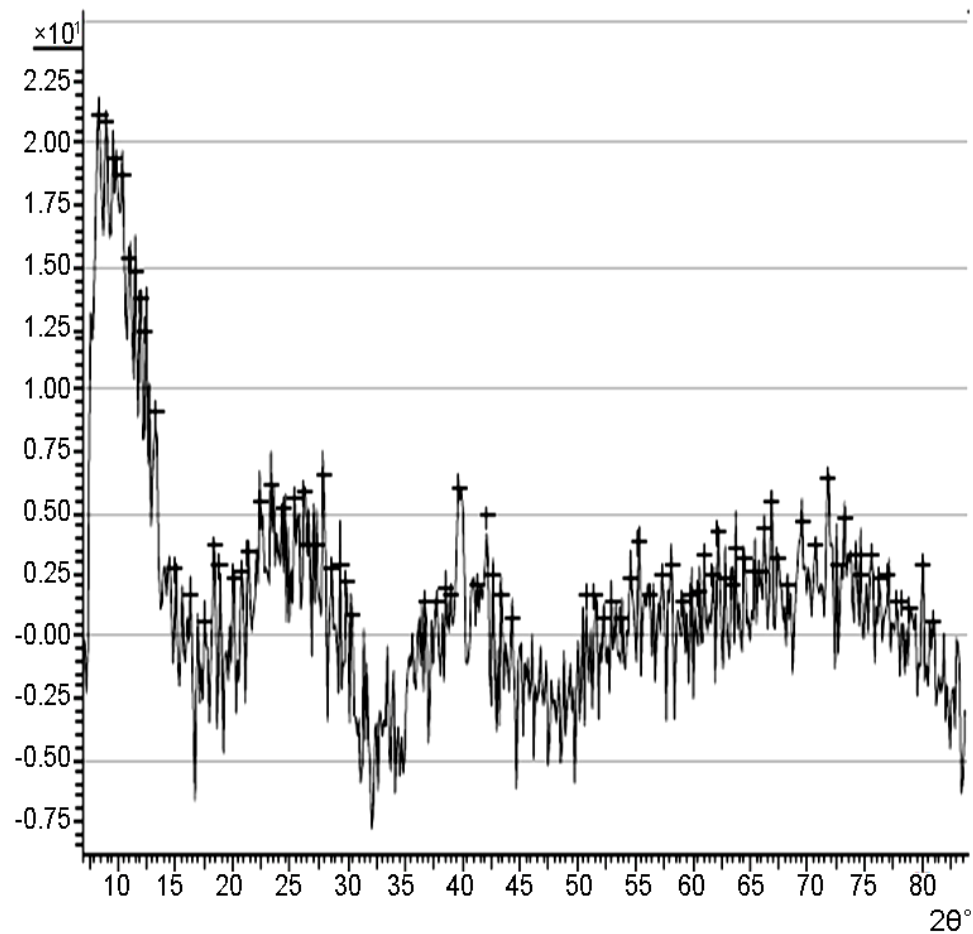

Figure 3. The XRD pattern of the $\mathrm{TiO}_{2}$ film prepared from the synthesized $\mathrm{TiO}_{2}$ powder.

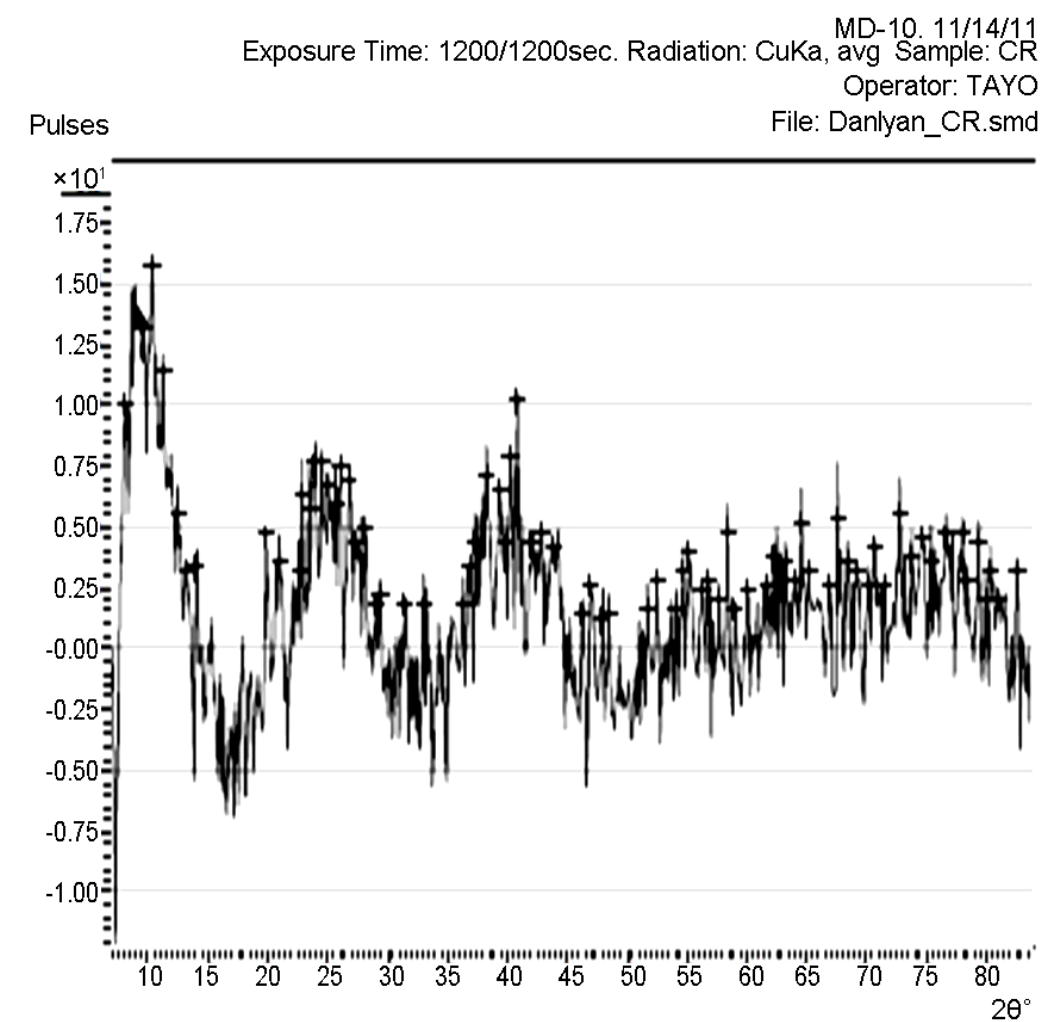

Figure 4. XRD pattern of $\mathrm{TiO}_{2}$ film prepared from the commercially available $\mathrm{TiO}_{2}$ powder. 
Figure 5 shows the comparison trend among the optical transmittance plots of the polyethylene oxide (PEO), synthesized and commercially available $\mathrm{TiO}_{2}$ solution. Figures 6 and 7 show the transmittance of their thin films on both the empty glass and the ITO glass. TA represents the transmittance of the solvent used (PEO), TS represents the transmittance of the synthesized sample and TR represents the transmittance of the commercially available sample.

The optical transmission spectra of the films, for both the synthesized and the commercially available samples in Figure 5, indicate that the synthesized $\mathrm{TiO}_{2}$ possessed higher transmission in the visible region of the spectrum than the commercially available one. This can be traced to the particle size difference between the two samples. That is, the synthesized sample is of smaller size.

Figures 6 and 7 indicated that the coated thin films showed excellent transparency, about 100\% over 285 and $1085 \mathrm{~nm}$ on the empty glass and 85\% (high transparency) on the ITO glass substrate, in the visible-light region of the spectrum. More so, it was shown that, the difference observed on the film deposited on the ITO glass is slight, compared to the one on the empty glass, which is very sharp. That is, the transmittance spectrum of nano $\mathrm{TiO}_{2}$ coating on ITO substrate was quite similar to that of bare substrates. To measure the energy band gap from the absorption spectra, a graph of $\alpha^{2}$ versus $\mathrm{E}(\mathrm{eV})$ is plotted as shown in Figures 8-11.

$$
\alpha=1 / d \operatorname{In}(1 / T)
$$

where $d$ is film's thickness, $T$ is transmittance and $\alpha$ is the absorption coefficient.

The linear extrapolation of the plot to energy axis gives the value of the energy band gap of the film. The value obtained for the synthesized sample was $3.95 \mathrm{eV}$ which agrees to $3.75 \mathrm{eV}$ obtained by [13] and comparable to $3.98 \mathrm{eV}$ obtained from the commercially available sample. The estimated value of the band gap for the film is larger than for the $\mathrm{TiO}_{2}$ bulk solid $(3.3 \mathrm{eV})$. It was assumed, according to [15] that the increase in the band gap is due to the quantum size effect (QSE), which occurs for semiconductor particles below $100 \mathrm{~nm}$. Also, this could also be inferred from the increment, 4.28 and $4.30 \mathrm{eV}$ observed respectively on the ITO films. These results are also in agreement with the values reported by [13,14,16-18].

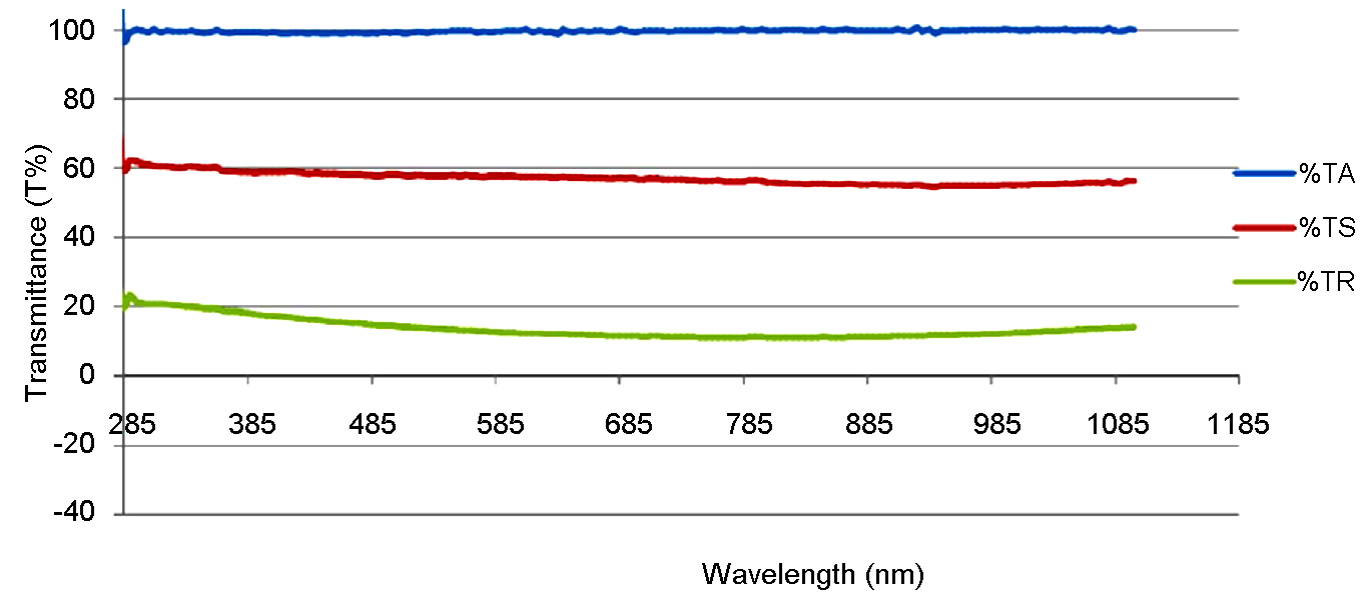

Figure 5. Optical transmittance plot of the PEO solution, synthesized and commercially available $\mathrm{TiO}_{2}$.

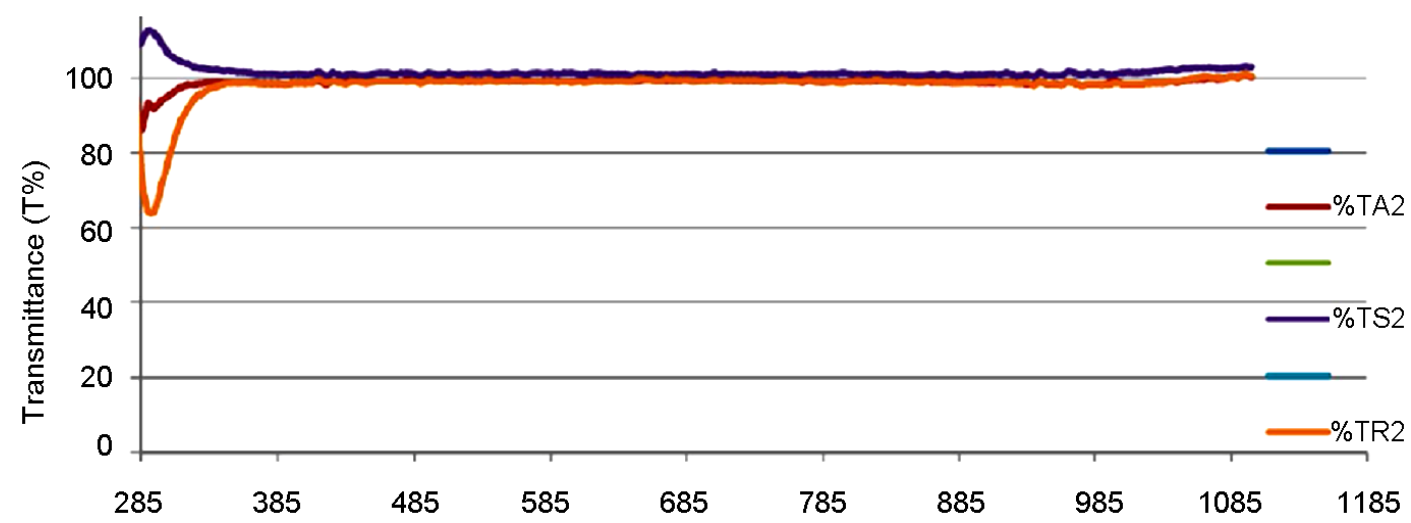

Figure 6. Optical transmittance plot of the PEO, the synthesized and commercially available $\mathrm{TiO}_{2}$ film. 


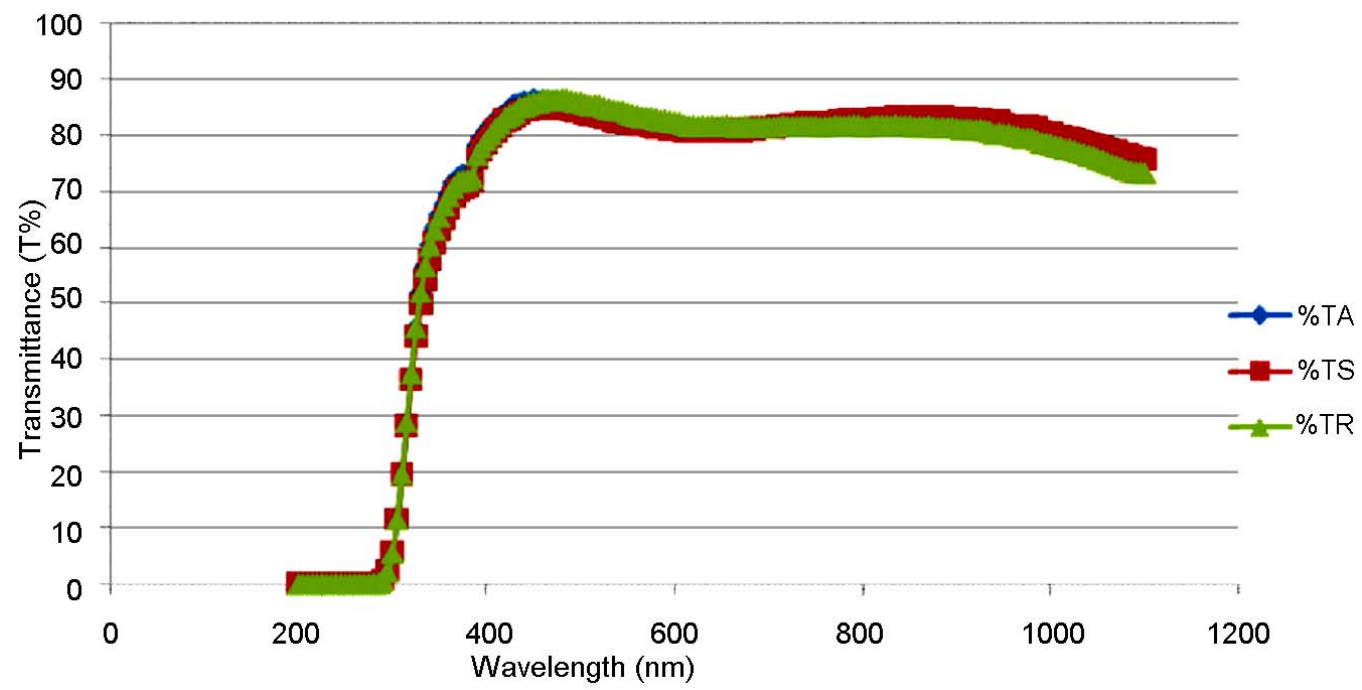

Figure 7. Optical transmittance plot of the PEO, the synthesized and the commercially available $\mathrm{TiO}_{2}$ film on $\mathrm{ITO}_{\text {glass. }}$

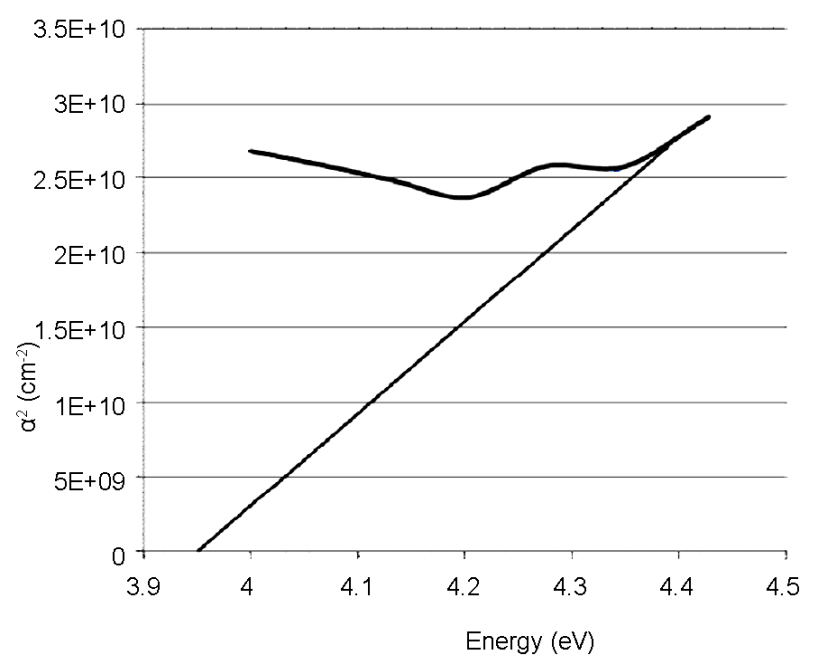

Figure 8. Absorption coefficient square $\left(\alpha^{2}\right)$ plots of the synthesized $\mathrm{TiO}_{2}$ on empty glass.

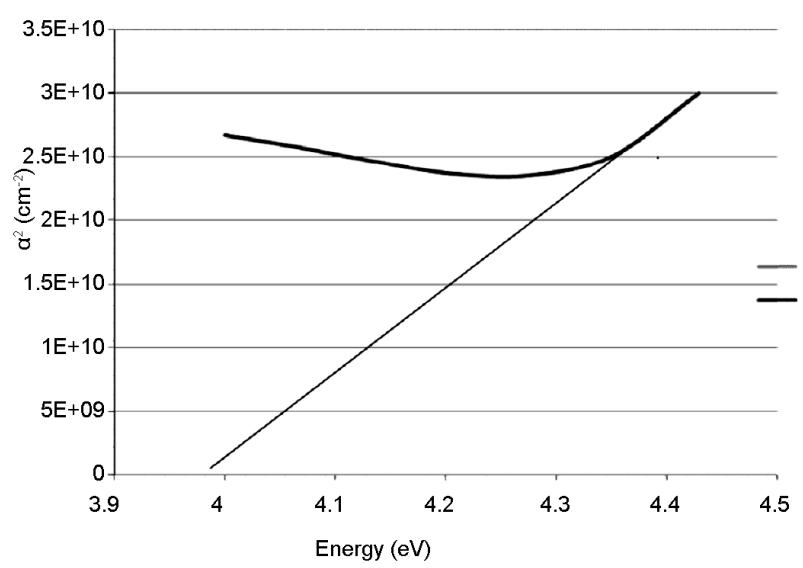

Figure 9. Absorption coefficient square $\left(\alpha^{2}\right)$ plots of the commercially available $\mathrm{TiO}_{2}$ on empty glass.

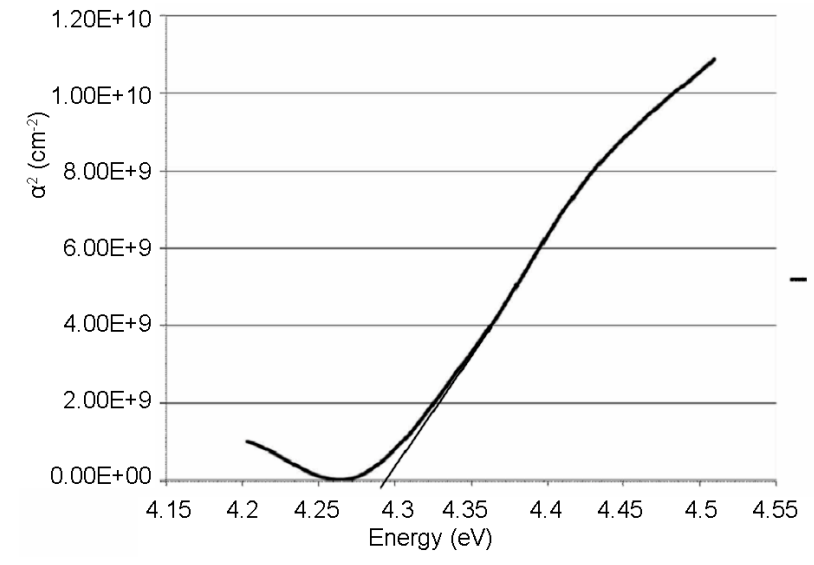

Figure 10. Absorption coefficient square $\left(\alpha^{2}\right)$ plots of the synthesized $\mathrm{TiO}_{2}$ on ITO glass.

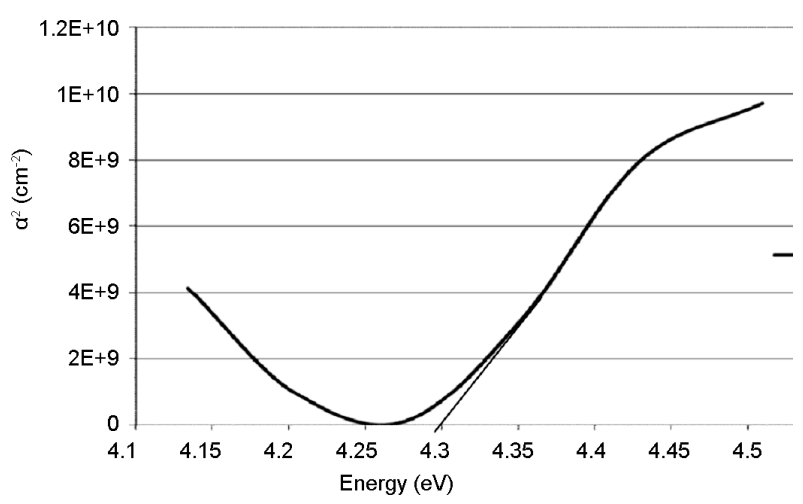

Figure 11. Absorption coefficient square $\left(\alpha^{2}\right)$ plots of the commercially available $\mathrm{TiO}_{2}$ on ITO glass.

\section{Conclusion}

The optical behaviour of the films was investigated at room temperature. It has been found that all the films 
were highly transparent; they showed high transmission in the visible region of the spectrum, which reveals relatively high surface smoothness without abnormal grain growth. The analysis of the spectra also showed that the film has an estimated energy band gap of $3.95 \mathrm{eV}$ on the empty glass and 4.28 on ITO substrate.

\section{Acknowledgements}

The authors appreciate the support provided by the management of Engineering Materials Development Institute, Akure, Nigeria where the entire bench work was carried out.

\section{REFERENCES}

[1] O. O. Adewoye, “Advances in Engineering Materials Development," Proceedings of Nigeria Materials Congress, Ile-Ife, 14-17 November 2007, pp. 118-122.

[2] C. X. Shan, X. Hou and K. Choy, "Corrosion Resistance of $\mathrm{TiO}_{2}$ Films Grown on Stainless Steel by Atomic Layer Deposition," Surface and Coatings Technology, Vol. 202, No. 11, 2008, pp. 2399-2402. doi:10.1016/j.surfcoat.2007.08.066

[3] Z. L. Tang, J. Y. Zhang, Z. Cheng and Z. T. Zhang, “Synthesis of Rutile $\mathrm{TiO}_{2}$ at Low Temperature," Materials Chemistry and Physics, Vol. 77, No. 2, 2001, pp. 314-317. doi:10.1016/S0254-0584(02)00003-2

[4] J. C. Yu, J. G. Yu, L. Z. Zhang and W. K. Ho, "Photocatalytic Activity of Nano-Sized $\mathrm{TiO}_{2}$ Powders by SolGel Method, Using Titanium Tetraisopropoxide and EtOH/ $\mathrm{H}_{2} \mathrm{O}$ Solution," Journal of Photochemistry and Photobiology A: Chemistry, Vol. 148, No. 1-3, 2002, pp. 263-271. doi:10.1016/S1010-6030(02)00052-7

[5] Y. Z. Li, N. H. Lee, E. G. Lee, J. S. Song and S. Kim, "Preparation and Characterization of Nano-TiO 2 Powder by Sol-Gel Method," Chemical Physics Letters, Vol. 389, No. 1-3, 2004, pp. 124-128. doi:10.1016/j.cplett.2004.03.081

[6] A. M. Ruiz, G. Sakai, A. Cornet, K. Shimanoe, J. R. Morante and N. Yamazoe, "Microstructure Control of Thermally Stable $\mathrm{TiO}_{2}$ Obtained by Hydrothermal Process," Sensors and Actuators B: Chemical, Vol. 103, No. 1-2, 2004, pp. 312-317. doi:10.1016/j.snb.2004.04.061

[7] S. Qiu and S. Kalita, "Synthesis, Processing and Characterization of Nanocrystalline Titanium Dioxide," Materials Science and Engineering: A, Vol. 435-436, 2006, pp. 327-332.

[8] S. F. Chen, J. P. Li, K. Qian, W. P. Xu, Y. Lu, W. X. Huang and S. H. Yu, "Large Scale Photochemical Synthesis of $\mathrm{M} @ \mathrm{TiO}_{2}$ Nano Composites $(\mathrm{M}=\mathrm{Ag}, \mathrm{Pd}, \mathrm{Au}, \mathrm{Pt})$ and Their Optical Properties, CO Oxidation Performance, and Antibacterial Effect,” 2010. www.springerlink.com
[9] J. Y. Choi, K. Kim, J. Yoo and D. Kim, "Properties of Cadmium Sulphide Films Deposited by Chemical Bath Deposition with Ultrasonication," Solar Energy, Vol. 64, No. 1-3, 1998, pp. 41-47. doi:10.1016/S0038-092X(98)00047-4

[10] D. S. Reddy, D. R. Reddy, B. K. Reddy, A. M. Reddy, K. R. Gunasekhar and P. S. Reddy, "Annealing Effect on Physical Properties of Thermally Evaporated MnS Nanocrystalline Films," Journal of Optoelectronics and Advanced Materials, Vol. 9, No. 7, 2007, pp. 2019-2022.

[11] R. K. Wahi, Y. Liu, J. C. Falkner and V. L. Colvin, "Solvothermal Synthesis and Characterization of Anatase $\mathrm{TiO}_{2}$ Nanocrystals with Ultrahigh Surface Area,” Journal of Colloid and Interface Science, Vol. 302, No. 2, 2006, pp. 530-536. doi:10.1016/j.jcis.2006.07.003

[12] M. Addamo, V. Augugliaro, A. Paola, E. García-López, V. Loddo, G. Marcì and L. Palmisano, "Photocatalytic Thin Films of $\mathrm{TiO}_{2}$ Formed by a Sol-Gel Process Using Titanium Tetraisopropoxide as the Precursor,” Thin Solid Films, Vol. 516, No. 12, 2007, pp. 3802-3807. doi:10.1016/j.tsf.2007.06.139

[13] B. H. Kim, J. H. Ahn, J. H. Jeong, Y. S. Jeon, K. O. Jeon and K. S. Hwang, "Preparation of $\mathrm{TiO}_{2}$ Thin Film on $\mathrm{SiO}_{2}$ Glass by a Spin Coating-Pyrolysis Process," $\mathrm{Ce}$ ramics International, Vol. 32, No. 2, 2006, pp. 223-225. doi:10.1016/j.ceramint.2005.01.016

[14] C. Randorn, J. Irvine and P. Robertson, "Synthesis of Visible-Light-Activated Yellow Amorphous $\mathrm{TiO}_{2}$ Photocatalyst," International Journal of Photoenergy, Vol. 2008, 2008, Article ID: 426872. doi: $10.1155 / 2008 / 426872$

[15] S. Ito, P. Chen, P. Comte, M. Khaja, K. Nazeeruddin, P. Liska, P. Péchy and M. Grätzel, "Fabrication of ScreenPrinting Pastes From $\mathrm{TiO}_{2}$ Powders for Dye-Sensitized Solar Cells," Progress in Photovoltaics: Research and Applications, Published online in Wiley InterScience, 2007. www.interscience.wiley.com

[16] M. Addamo, V. Augugliaro, A. Paola, E. García-López, V. Loddo, G. Marcì and L. Palmisano, "Photocatalytic Thin Films of $\mathrm{TiO}_{2}$ Formed by a Sol-Gel Process Using Titanium Tetraisopropoxide as the Precursor," Thin Solid Films, Vol. 516, No. 12, 2008, pp. 3802-3807. doi:10.1016/j.tsf.2007.06.139

[17] S. Ito, T. Takeuchi, T. Katayama, M. Sugiyama, M. Matsuda, T. Kitamura, Y. Wada and S. Yanagida, "Conductive and Transparent Multilayer Films for Low-Temperature-Sintered Mesoporous $\mathrm{TiO}_{2}$ Electrode of Dye-Sensitized Solar Cells," Chemistry of Materials, Vol. 15, No. 14, 2003, pp. 2824-2828. doi:10.1021/cm021051t

[18] P. S. Raghupathi, J. George and C. S. Menon, “The Effect of Deposition Rate on Electrical, Optical and Structural Properties of ITO Thin Films," E-Journal of Chemistry, Vol. 2, No. 3, 2005, pp. 171-177. doi:10.1155/2005/879524 